\title{
Contactless Palm Vein Authentication Security Technique for better Adoption of E-Commerce in Developing Countries.
}

\author{
Sunday Alabi', Martin White', Natalia Beloff \\ University of Sussex, Falmer, Brighton, UK
}

\begin{abstract}
E-commerce has contributed immensely to the economies of developed countries and a factor in its success can be attributed to the adoption of e-commerce by their citizens. As such, it is perceived that ecommerce can also be an economic driver for developing countries. However, security has been identified as a major barrier that prevents citizens from adopting e-commerce in developing countries. Therefore, this paper examines Security Authentication Techniques (SAT), particularly Digital Signature (DS) and Digital Fingerprint Systems (DFS), including the limitations of these two security techniques, and then proposes Contactless Palm Vein Authentication (CPVA) as a potentially much better solution to increase adoption of e-commerce in developing countries. The architecture of this new CPVA technique is discussed in relation to Security, Privacy, Trust and Reliability. Participants are treated to a Design Fiction Documentary (DFD) and Design Fiction Simulation Experiment (DFSE) in our experimental design method to measure the potential Technology Acceptance (adoption) of the proposed CPVA technique over DS and DFS authentication techniques. The result of our pilot study indicates that citizens may be willing to adopt the proposed CPVA technique, which may increase their trust and likely adoption of more e-commerce applications. A larger main study is planned in the field in Nigeria starting January 2020.
\end{abstract}

Keywords: Palm Vein, Design Fiction, Reliability.

\section{Introduction}

Nigeria is the largest African country [1], [2] with a population of 180 million, which has grown rapidly in the last 20 years. There is plenty of good fertile land for agriculture and other natural resources. All countries in Africa are still either underdeveloped or developing countries. Nigeria is located on the African continent and is one of the countries of the sub-Sahara region [1], [3]. Most of these countries have unstable economies and this is affecting the economic development of that continent. In actual fact, their economic problems can also be attributed to a lack of infrastructural facilities and poor governance [4]. Non-adoption of e-commerce by citizens also contributes to stunted growth of their economies [1].

E-commerce is an online transaction processing (OLTP) technology in which the system responds immediately to user requests [5], [6]. This technology has made the world a global village comprised of many opportunities. Online transactions are ways of carrying out transactions via the Internet and it has been described as the new driver for economic growth especially for developing countries [4]. This provides a great opportunity for organizations, individuals and nations at large.

However, issues of security have been identified as a factor limiting e-commerce development and its total adoption in developing countries [7], [8]. Crime associated with theft and data manipulations are often detected [9]. One of the reasons why identify theft is so widespread is due to ineffective security measures. The most common method, at this time, of identity verification is based on digital identity and signature. These methods of security use: code, e.g. passwords and other behavioural features, to identify the person. However, all of these features are relatively easy to steal or forge, therefore, they are not effective identity verification or authentication methods [10].

Another security measure is fingerprints authentication. Okechukwu and Majesty argued in [11], [12] that it is necessary to introduce forensic methods of security into the e-commerce of developing countries so as to uplift the adoption rate of citizenry and benefits of e-commerce. Introduction of fingerprint identification into ecommerce applications make the system more secure and alleviate citizens' fear to a certain extent, that is, until the weakness of Digital Fingerprint Systems (DFS) becomes more apparent [13]. Due to the nature of many people's work, particularly those are who are involved in manual labour, damage to the finger tips are sustained and this leads to the DFS failing to recognize the user fingerprint. This means that at the moment, this method is not effective for many people. Therefore, introduction of a new method called Palm Vein Authentication becomes important.

Palm Vein Authentication (PVA), is a digital security technique that uses an individual vein pattern as personal authentication and identification data [14]. The research work outlined in this paper investigates the 
possibility of introducing Palm Vein Authentication to enhance e-commerce applications in developing countries focusing on Nigeria. Palm Vein Identification uses the unique internal vein pattern of the palm as a transactional authentication method. Its benefits are uniqueness, difficult to forge, secure and reliable [14], [15]. This method will help citizens of Nigeria and other developing countries since vein of the palm cannot be easily damaged due to dryness and by citizens engaging in hard labour using the hands.

The rest of this research paper is organised as follows: section 2 discusses the research background, while section 3 explains the research questions. Section 4 discusses the methodological approach used, section 5 explains the experimental approach, section 6 briefly presents the pilot study results, which lead the way to conduct a more exrtnsive full study in the field in Nigeria (discussed in future work). Section 7 discusses our results so far in more detail. Finally, setcion 8 draws some conculesions and states the future work.

\section{Research Background}

This research will consider the security aspects of user identification transaction systems, e.g. payment in ecommerce application, election authentication, access to e-government and e-health services, building access, etc. in developing countries, specifically focusing on Nigeria as a case study.

A Design Fiction [16] approach will be used to educate users on security issues associated with user identification transactions. In particular, the Design Fiction will illustrate the use of Digital Signature (DS, e.g. pin, password) [17] [18], DFS [19] and Contactless Palm Vein Authentication (CPVA) [20] to authenticate (authorise) access to user identification transaction systems (UITS). The research project builds a simulation of an e-commerce application that will accept DS, DFS and CPVA access to a UITS, where in this case the UITS will be a simulated payment system, i.e. a simulation model that deploys various technology prototypes, and existing ICTs to implement the scenarios depicted in a Design Fiction [21]. For the purposes of the study, the Design Fiction will encompass an e-commerce shopping application that will be developed to facilitate measurement of the users acceptance of transactional risk based on the user identification method, i.e. the intervention (DS, DFS or CPVA) with a focus on palm vein authentication [22], [23].

The main aim of this research is to investigate the advantages of CPVA over DS and DFS technologies, and to determine how factors such as: security, awareness, trust, privacy, cost, digital identity theft, etc. (see Fig. 2) might affect the adoption of CPVA in Nigeria's existing IT infrastructure [24]. It is well reported in the literature that Nigerian Citizens do not have a high level of trust in Nigeria's current unsecure e-commerce platforms, thereby making them uncomfortable in engaging with e-commerce applications that require them to divulge personal and financial information [25]. This research aims to investigate how Nigerian e-commerce users may change their risk perception when using more secure technologies, such as CPVA. This study examines how the current use of DS security techniques has led to pervasive digital identity theft that has resulted in extensive fraudulent activities. This has led to a large degree of mistrust of e-commerce applications in Nigerian society similar to that reflected in other African countries [3], [4]. This level of distrust has to be improved with new technologies, such as CPVA, that are perceived to be able to deliver a high-level security.

\section{Research Questions}

The following research questions considered for the purpose of this research work:

1. Do biometric authentication techniques such as fingerprints, palm vein, iris, retina, Voice recognition system, facial image and digital signature overcome the 'fear and distrust' associated with e-commerce applications?

2. How can we convince the Nigerian citizen that new digital security methods, such as CPVA, can provide adequate protection against different fraudulent acts for typical e-commerce applications?

3. Will the level of risk perceived by the Nigerian citizen be adequately reduced to facilitate wider adoption of e-commerce applications if such applications implement CPVA for their user identification transaction system?

The literature survey provides ample evidence for the efficacy of iris, retina and facial image scanning, and so is not considered in this study [12], [26]. A Design Fiction has been developed to educate the Nigerian citizen on the level of security established in different e-commerce applications using DS, DFS, and CPVA to facilitate answers to these research questions. 


\section{Methodology}

This Design Fiction based experimental research method will measure the perceived level of risk that Nigerian citizens will adopt when using new security technologies, such as CPVA. The method will examine the impact of changing an independent variable (i.e. the factors: security, risk, fear, Web Assurance Seals Services (WASS), which relates to Trust, and usability, of an e-commerce application) to measure its effect on the dependent variable (Intention to Adopt) and therefore provide insight into the effects and consequences of distrust associated with the users' involvement, engagement and interactivity in their online experience of ecommerce using the Design Fiction (Documentary and Simulation Experiment) and their associated treatments.

The DF treatment is composed of a Design Fiction Documentary (DFD) shown to all participants, and a prototype development of an e-commerce application, i.e. a simulation incorporating CPVA, called the Design Fiction Simulation Experiment (DFSE) treatment. The overall DF treatment (i.e. DFD + DFSE) is followed by a post treatment survey, which is a detailed questionnaire, designed to elicit information around 'Intention to Adopt' from the subject participants based on the hypotheses (coded as H2d, H4a, and so on, see Fig. 1 and Fig. 2) that link the independent variables to the dependent variable. Fig. 1 and 2 illustrate the e-commerce trust model entity relational diagram linking independent variable to the dependent variable.

The associated hypothesis and questionnaire are too long and detailed to include in this paper, however they can be accessed in the GitHub archive for this project ${ }^{1}$.

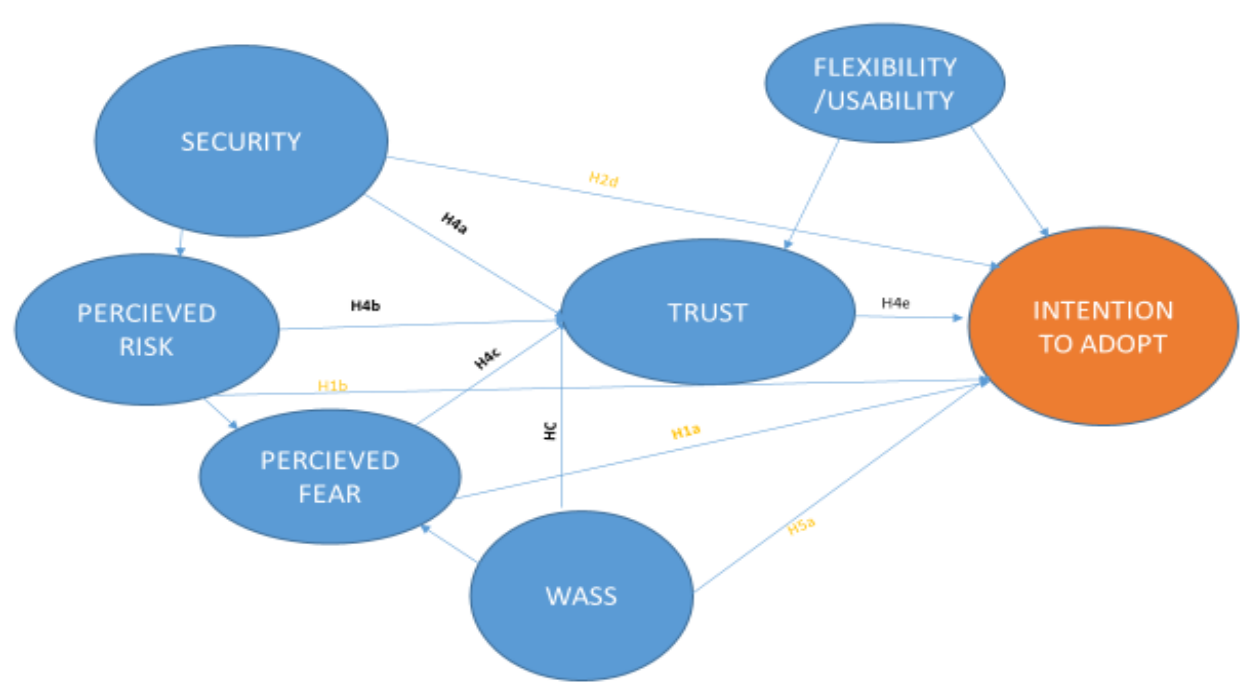

Fig.1. Overview of the e-commerce Trust Model illustrating the experimental variables relationship

We can see from Fig. 2 that many other factors affect users' perceived fear, risk, security, usability and so on, hence intention to adopt e-commerce. For example, technology factors around security such as use of CPVA, DS, DFS, a user's perception of whether their finger print will work, fear of digital identify theft, privacy issues all impact trust and intention to adopt. How aware the user is concerning security of e-commerce, what previous experience they have had, and specifics of that awareness also affect their perceived risk, hence trust of e-commerce and their subsequent intention to adopt.

\footnotetext{
${ }^{1}$ https://github.com/sundayalabi/
} 


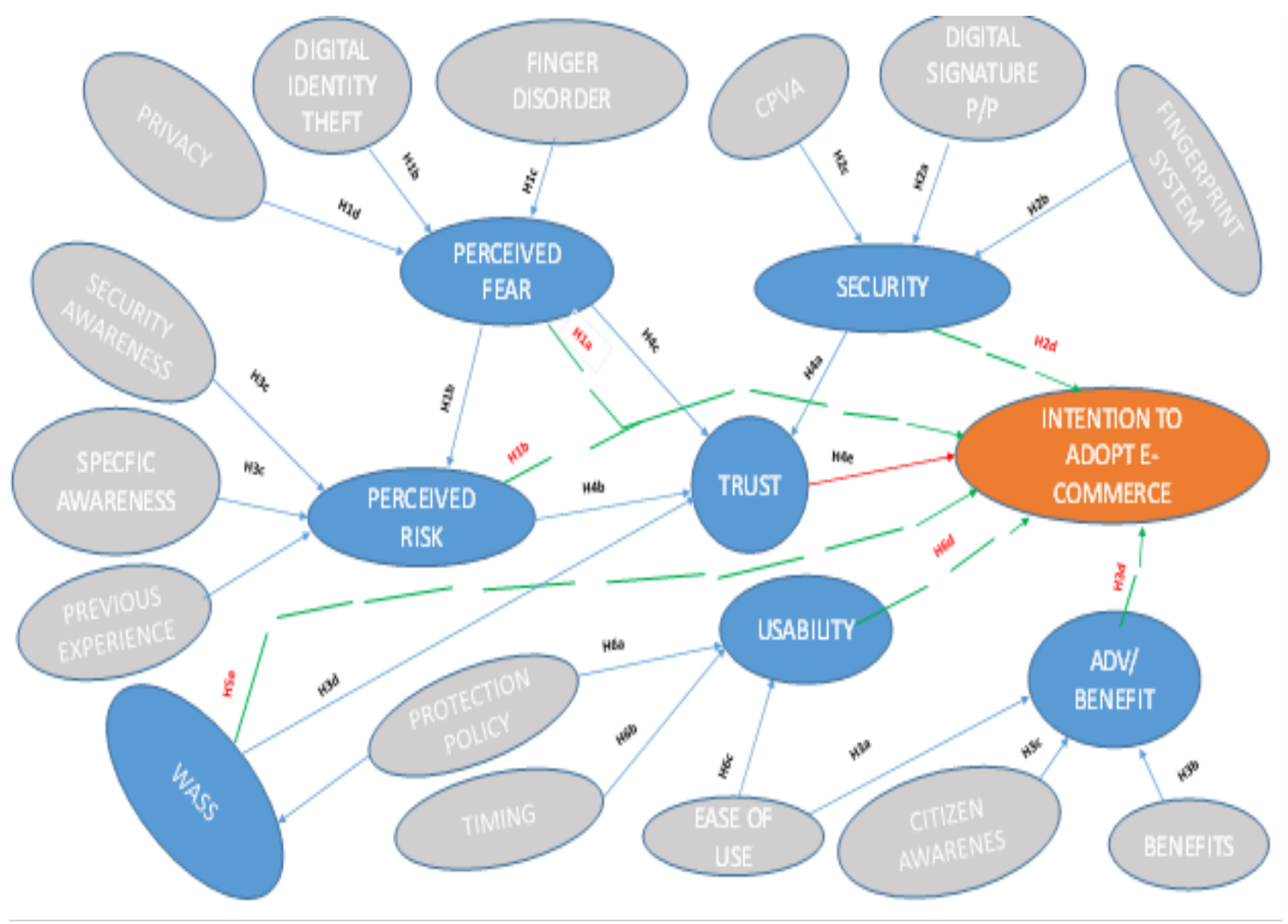

Fig.2. Detailed Research Model Entity Relation linking independent and dependent variables

\section{Experimentation}

The experiment focuses on the use of a Design Fiction based treatment to first explain and educate the user on the benefits of CPVA, in terms its advantages over DS and DFS, with respect to securing and building trust worthy e-commerce transactional applications - this is the DFD. Then the developed DFSE task (i.e. a CPVA based e-commerce simulation) task will be taken by each participant using Within Subjects Design - here, each participant is exposed to every factor in the DFSE treatment (i.e. manipulation of all the different levels of the independent variables) to measure their Intention to Adopt e-commerce in their daily lives.

After completing the DFSE (CPVA based) experimental tasks, each participant will complete the postexperimental survey. The DF based treatment and survey will be conducted in the chosen area Centre (e.g. community hall in a Nigerian town). Thus, the design of each experiment includes a structured questionnaire (post-experimental survey), DFD (an explanation of the issues concerning e-commerce transactions) and the DFSE based on a CPVA paradigm (the e-commerce simulation). Appropriate subjective measures in the form of post-experiment questionnaires are selected for analysis.

The population of this research includes chosen categories of citizens of Nigeria. The volunteers (samples) are eligible to partake in the study whether they are experienced with e-commerce applications or not. Participants will be invited to participate as an individual. Participants will be randomly assigned to the treatment, (i.e. all participants will be selected for the DFD and randomly assigned the DFSE factors in the Within Subjects Design). Generally, with random assignment, participants have an equal chance of being assigned to a specific treatment (one of the factors or independent variables) to eliminate or reduce bias in the research [27]. In this case, with our Within Subjects Design, participants are randomly assigned to the order of being exposed to the independent variables (factors). Within Subjects Design has advantages besides cost efficiencies (half as many participants needed) such as providing control of extraneous participant variables because all participants have the same characteristics for each factor being tested - each participant(s) has the same mean IQ, socio-economic background, and so on because they are the same people [28]. Further, carry over effects are considered well ${ }^{2}$.

\footnotetext{
2 https://www.students4bestevidence.net/blog/2018/08/23/carryover-effects-what-are-they-why-are-theyproblematic-and-what-can-you-do-about-them/
} 
Randomly selected and randomly assigned participants also increases the external and internal validity repectively. The experiment so far involves a small pilot of 50 participants that are Nigerian students in the University of Sussex, to test the experimental method and fine tune the process. The result of the pilot study was used to validate the designed-questionnaires, refer to the GitHub archive, and the final experimental methodology. The structured questionnaires will be administered after the DFSE (CPVA based) experimental task is completed by the participants.

Fig. 3 indicates the experimental method whereby the sample users are randomly selected to the e-commerce education using a Design Fiction Documentary (DFD), and randomly assigned to the Design Fiction Simulation Experiment (DFSE) - order of treatments is randomised per participant, i.e. the CPVA e-commerce simulation - using a Within Subjects Design for economical and statistical efficiency [16], [21]. DFD and DFSE is then followed by a Post-Survey.

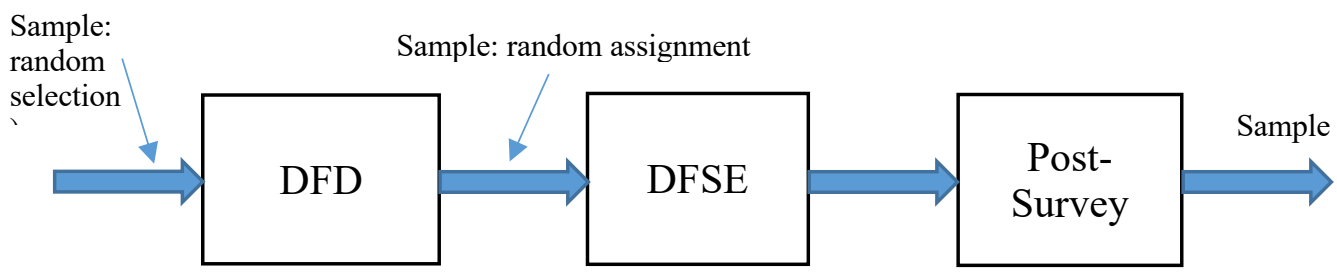

Fig.3. The 'within subjects design' experimental model

\section{Pilot Study Result}

The Design Fiction Documentary (DFD) and Design Fiction Simulation Experiment (DFSE) were tested using a minimum number of participants that are citizens of developing countries who were already accustomed with the experience of e-commerce in developing countries. After the DFD, a DFSE was completed followed by the questionnaire survey administration. A questionnaire that comprises of sixteen sections was used to take feedback data from the participants after the conduct of the experiment. The results gathered includes the previous experience of computer usage and Internet and e-commerce transaction of participants. How the dependent variable (Intention to Adopt) are being affected by independent variables are also tested.

Note, from Fig 1. we can also think of Trust as an Independent variable that is manipulated to see the effects on the dependent variable Intention to Adopt, or we can think of Trust as a dependent variable that we measure after manipulating independent variables such as fear and risk, etc.

The pilot results significantly indicates that citizens of developing countries want a better security authentication technique, which may increase the citizen's trust in e-commerce. Again, the pilot result shows that, citizens may better accept the proposed CPVA architecture compared to existing DS and DFS based ecommerce transactions.

In our pilot study, DS based on Pin and Password is actually rejected due to its vulnerability that leads to citizens Identity theft, where citizens Identity theft reduces citizen's trust towards e-commerce. The pilot study result also shows that, DFS provides a more secure platform than the DS architecture. Also, further inference is shown that DFS based identification has denied several citizens from their rightful authentication thereby increasing citizen's fears over e-commerce security and this probably leads to e-commerce rejection. The result of citizens perspectives towards these DS and DFS security authentication techniques suggest that citizens may prefer the proposed security architecture based on Contactless Palm Vein Authentication (CPVA) when carrying out their day to day e-commerce transactions. Raw data results can be found in the GitHub archive previously mentioned.

\section{Discussion}

Building acceptable trusted e-commerce systems is desperately needed in developing countries to ensure the survival of their economies [3]. Research has shown that specific infrastructural barriers are limiting and also negatively affecting e-commerce growth in developing countries [1]. P. Japhet et al have argued that framework barriers are a hindrance [8]. Other evidence suggests that the causes of e-commerce non-development among developing countries varies [29]. Billewar and Babu argue that it is unbelievable that many developing countries did not have any policy for protecting customers for online transactions [30]. Therefore, customers are not secure and are not able to resolve their problems, which reduces customer trust in e-commerce [31]. This research work investigates many salient barriers affecting e-commerce development and uptake in these areas. 
K. E. Corey et al. [5] show that e-commerce is advancing on a daily basis and benefiting individuals, organizations and nations at large to the extent of it being an economic catalyst in this present day's economy, and this prevalence of e-commerce makes it vulnerable to attacks. E-commerce rapid growth makes an ecommerce platform attack to be more prone and frequent [8]. Further, attacks are now becoming more advanced in nature, as such these attacks are now becoming a major barrier to e-commerce growth in developing countries [10]. Therefore, e-commerce security issues are very important and pertinent, as such this research considers the security aspect of electronic commerce using a Contactless Palm Vein Authentication (CPVA) as a superior method for securing e-commerce transactions. Other research work discusses I-based passwords, finger print, finger vein and palm vein security technologies used for e-commerce transaction authentications [32], [23], [33]

Digital Signature involves the use of codes as a password for identity representation on an e-commerce platform [32]. In many cases, used have experienced losses due to stolen pin and password at alarming rates. This identity theft has impacted negatively on the development of e-commerce in developing countries [8]. However, the success of e-commerce may also impact positively on the economic situation of developing countries if security issues and identified barriers to uptake are successfully resolved [1].

The incorporation of biometrics to the PIN system has increased the security system in online transactions [29]. Although, despite security awareness customers are still often careless with their Pins and Password information, which increases the rate at which fraudsters are able to succeed in guessing their Pin or Password credentials. Evidence shows that several cases of identity theft have shown the need for new methods to improve the security aspect of e-commerce. However, more secure authentication is achieved using biometric techniques in which an individual unique identifier is used for authentication [17], [19], [34]. Physiological and behavioural features are proving to be more reliable in digital security identification [35] .

Evidence shows that the fingerprint technique is not very effective for many citizens of developing countries, often due to nature of manual employment that degrades a person's physical fingerprints. Whenever the outer layer of the finger is subjected to damage, then the DFS begins to experience High False Rejection Rates (HFRR) [13], you can see this if you do some simple DIY at home, often you can't access your own mobile phone afterwards using DFS. Therefore, DFS at the moment may need to be replaced in online transactions in developing countries. However, the palm vein technique is unique for an individual, and this vein pattern under the palm can be captured with the use of an infrared camera [36]. Veins are tissues through which the blood flows in the body and the vein at the region of the palm is referring to as a Palm Vein [37]. Hand vein geometry is still at an early research stage [38] . Therefore, existing IT infrastructure may not be adequate for new CPVA security mechanisms?

However, there are examples of CPVA currently being used in a hospital to authenticate patients [39] . In such cases, sample palm vein images are being acquired from incoming patients using an infrared camera. The vein pattern of a particular patient is then used to compare with the already processed pattern in the database of the patient's medical records [40]. Laadjel M. et. al argues in [26] and M. Preethi in [22] argued that it will not be easy to steal palm vein patterns due to its complex structure and the authentication requires live blood flow through the veins. Also, Jain argues that the palm vein pattern is very likely to be more secure than a DFS [41].

Krishneswari and Arumugam show [42] show that the positive characteristics of CPVA that make this authentication method superior to DFS include:

1. CPVA systems are capable of using a pre-registered image of an individual's identity and comparing with the newly acquired image using blood veins palm pattern.

2. CPVA systems are likely to be acceptable by the user because of its non-invasiveness and the technique of using live blood veins makes the method very reliable.

3. CPVA images are difficult to replicate, this makes the technique highly dependable.

\section{Conclusion}

Security authentication methods for e-commerce transactions is attracting many researchers' attention, especially in developing countries. Their focus is on how new improved authentication techniques could be developed to increase e-commerce adoption in developing countries. The privacy, security and trust aspects have been attracting research interest since they are considered as critical issues and challenges for e-commerce adoption in developing countries. This paper reviewed a number of architectures for security authentication technique issues related to the privacy and security of e-commerce transactions.

This paper discussed the DS (Pin/Password) concept and challenges of identity theft. At the same time DFS technology architecture was reviewed, its effectiveness and the problem of High False Rejection Rate (HFRR) is discussed. In addition, this paper examined the problems associated with current security 
techniques. Furthermore, we proposed a new security architecture, focused on CPVA, to be used in the authentication of e-commerce in developing countries. This may overcome the issues apparent in DS and DFS architectures, particularly in relation to security and privacy since these are important in providing the adequate trust needed by the citizens. The proposed CPVA technology has a property that supports liveliness (i.e. the palm veins must have blood flowing to work), integrity, privacy and reliability.

\section{$8 \quad$ References}

[1] S. Oluyinka, A. Shamsuddin, M. A. Ajabe, and W. I. Enegbuma, "A study of electronic commerce adoption factors in Nigeria,” Int. J. Inf. Syst. Change Manag., vol. 6, no. 4, p. 293, 2013.

[2] A.-A. O. Emmanuel, "Adoption of E-commerce in Nigerian Businesses: A change from traditional to e-commerce business model in Richbol Environmental Services Limited," Thesis Dissertation, Business School, Seinajoki University of Applied Sciences, Finland, p. 110, 2012.

[3] J. E. Lawrence, "The Growth of E-Commerce in Developing Countries: An Exploratory Study of Opportunities and Challenges for SMEs," International Journal of ICT Research and Development in Africa (IJICTRDA), vol 2, no 1, pages 11, 2011.

[4] P. M. Kanyaru and J. K. Kyalo, "Factors Affecting the Online Transactions in the Developing Countries: A Case of E-Commerce Businesses in Nairobi County, Kenya,” J. Educ. Policy Entrep. Res., vol. 2, no. 3, pp. 1-7, 2015.

[5] K. E. Corey, M. I. Wilson, and E. Lansing, “e-Business and e-Commerce,” Elsevier Inc, pp. 285-290, 2009.

[6] S. M. Al-najjar and M. K. Jawad, "Measuring Customers ' Perceptions and Readiness to Accept E-Commerce in Iraq : An Empirical Study,” Journal of Marketing Management, vol. 4, no. 1, pp. 151-162, 2016.

[7] M. A. Shouk and M. I. Eraqi, "Perceived barriers to e-commerce adoption in SMEs in developing countries: the case of travel agents in Egypt," Int. J. Serv. Oper. Manag., vol. 21, no. 3, pp. 332, 2015.

[8] P. Japhet E. Lawrence, Usman A. Tar, "Persistent Barriers to E-commerce in Developing Countries," J. Glob. Inf. Manag., vol. 19, no. 3, pp. 30-44, 2011.

[9] A. N. Nikitkov and D. Bay, "Online Auction Fraud: An Empirical Analysis of Shill-bidding Practice," J. Forencic Investig. Account., vol. 2, no. 3, 2010.

[10] C. Ayo, “A Framework for e-Commerce Implementation: Nigeria a Case Study.,” J. Internet Bank. Commer., vol. 13, no. 2, pp. 1-12, 2008.

[11] O. G. Okwuchukwu, "Access To and Pattern of ICT Use among Undergraduate Students of Nnamdi Azikiwe University , Awka-Nigeria," International Journal of Humanities and Social Science (IJHSS ), vol. 2, no. 1 pp. 1$11,2015$.

[12] M. Okechukwu and I. Majesty, “ATM Security Using Fingerprint Biometric Identifer: An Investigative Study,” Int. J. Adv. Comput. Sci. Appl., vol. 3, no. 4, pp. 68-72, 2012.

[13] S. Yoon, J. Feng, and A. K. Jain, “On latent fingerprint enhancement," Conference Proceeding, Biometric Technology for Human Identification, vol. 2, 2010.

[14] M. Sayed, "Palm Vein Authentication Based on the Coset Decomposition Method," Journal of Information Security, vol. 6, no. 3 July, pp. 197-205, 2015.

[15] P. A. Kumari and G. J. Suma, “A Novel Multimodal Biometric Scheme for Personal Authentication,” Int. J. Res. Eng. Technol., vol. 2, no. 2, pp. 55-65, 2014.

[16] P. Coultron, J. Lindley, and H. A. Akmal, "Design Fiction: Does the search for plausibility lead to deception?," Proc. DRS 2016, Des. Res. Soc. 50th Anniv. Conf., pp. 1-16, 2016.

[17] D. Kumar, S. Engineer, I. Solutions, and P. Limited, "A Review in Various Approaches of Feature Extraction and Feature Fusion in Multimodal Biometric System,” IJSRSET, vol. 3, no. 3, pp. 734-739, 2017.

[18] J. D. Hemamalini M., "Two Step Verification for Withdraw the Amount from ATM Machine," Int. J. Adv. Res. Comput. Sci. Softw. Eng., vol. 4, no. 9, pp. 698-702, 2014.

[19] I. G. Dakhil and A. A. Ibrahim, "Design and Implementation of Fingerprint Identification System Based on KNN Neural Network," J. Comput. Commun., vol. 06, no. 03, pp. 1-18, 2018.

[20] S. Elnasir, S. M. Shamsuddin, and S. Farokhi, "Accurate palm vein recognition based on wavelet scattering and spectral regression kernel discriminant analysis," J. Electron. Imaging, vol. 24, no. 1, pp. 1-24, 2015.

[21] S. Grand and M. Wiedmer, "Design Fiction: A Method Toolbox for Design Research in a Complex World," Designresearchsociety.Org, pp. 1-25, 2006.

[22] M. Preethi, D. Vaidya, S. Kar, A. M. Sapkal, and M. A. Joshi, "Person Authentication Using Face And Palm Vein : A Survey Of Recognition And Fusion Techniques," International Journal of Technology Enhancements and 
Emerging Engineering Research, VOL 3, ISSUE 03 vol. 3, no. 03, pp. 55-69, 2015.

[23] I. Sarkar, F. Alisherov, T. H. Kim, and D. Bhattacharyya, "Palm vein authentication system: A review," Int. J. Control Autom., vol. 3, no. 1, pp. 27-34, 2010.

[24] M. A. Alqahtani, A. H. Al-Badi, and P. J. Mayhew, "The enablers and disablers of e-commerce: Consumers' perspectives,” Electron. J. Inf. Syst. Dev. Ctries., vol. 54, no. 1, 2012.

[25] K. K. Kim and B. Prabhakar, "Initial trust, perceived risk, and the adoption of internet banking," Icis, pp. 537-543, 2000 .

[26] M. Laadjel, A. Bouridane, O. Nibouche, F. Kurugollu, and S. Al-Maadeed, "An improved palmprint recognition system using iris features,” J. Real-Time Image Process., vol. 8, no. 3, pp. 253-263, 2013.

[27] A. Bryman, "Barriers to Integrating Quantitative and Qualitative Research," J. Mix. Methods Res., vol. 1, no. 1, pp. $8-22,2007$

[28] N. S. Gray, R. J. Snowden, M. Peoples, D. R. Hemsley, and J. A. Gray, "A demonstration of within-subjects latent inhibition in the human: limitations and advantages," Behav. Brain Res., vol. 138, no. 1, pp. 1-8, Jan. 2003.

[29] K. Kavitha and K. Kuppusamy, “A hybrid biometric authentication algorithm,” Int. J. Eng. Trends Technol., vol. 3, no. 3, pp. 311-319, 2012.

[30] S. R. Billewar and D. H. Babu, “Approach to Improve Quality of E-Commerce,” Int. J. Recent Technol. Eng., vol. 1, no. 5, pp. 36-39, 2012.

[31] O. Osho, C. I. Onuoha, J. N. Ugwu, and A. A. Falaye, "E-commerce in Nigeria: A survey of security awareness of customers and factors that influence acceptance," CEUR Workshop Proc., vol. 1755, pp. 169-176, 2016.

[32] M. S. Hwang, S. K. Chong, and T. Y. Chen, "DoS-resistant ID-based password authentication scheme using smart cards," J. Syst. Softw., vol. 83, no. 1, pp. 163-172, 2010.

[33] L. Hong, Y. Wan, and A. Jain, "Fingerprint image enhancement: Algorithm and performance evaluation," IEEE Trans. Pattern Anal. Mach. Intell., vol. 20, no. 8, pp. 777-789, 1998.

[34] V. M. Jr and Z. Riha, "Biometric Authentication Systems," FI MU Rep. Ser., vol. 2, no. November, pp. 1-46, 2000.

[35] D. Abrazhevich, "Electronic Payment Systems : a User-Centered Perspective and Interaction Design", Proefschrift ISBN 90-386-1948-0, 2004.

[36] A. Arakala, H. Hao, S. Davis, and K. J. Horadam, "The Palm Vein Graph - Feature Extraction and Matching," Proc. 1st Int. Conf. Inf. Syst. Secur. Priv., no. 2015, pp. 295-303, 2015.

[37] S. Crisan and B. Tebrean, "Low cost, high quality vein pattern recognition device with liveness Detection. Workflow and implementations," Meas. J. Int. Meas. Confed., vol. 108, pp. 207-216, 2017.

[38] D. Huang, X. Zhu, Y. Wang, and D. Zhang, "Dorsal hand vein recognition via hierarchical combination of texture and shape clues," Neurocomputing, vol. 214, pp. 815-828, Nov. 2016.

[39] N. Kaur, "Vein Pattern Recognition: A secured way of Authentication,” Int. J. Eng. Comput. Sci., vol. 5, no. 10, pp. $18377-18383,2016$.

[40] W. Y. Han and J. C. Lee, "Palm vein recognition using adaptive Gabor filter," Expert Syst. Appl., vol. 39, no. 18, pp. 13225-13234, 2012.

[41] V. K. Jain, “A Tehnique To ROI Of Palmprint For Palmline Matching,” International Journal of Engineering Research and Applications (IJERA) vol. 2, no. 6, pp. 1007-1009, 2012.

[42] K. Krishneswari and S. Arumugam, “A Review on Palm Print Verification System,” Int. J. Comput. Inf. Syst. Ind. Manag. Appl., vol. 2, pp. 113-120, 2010. 